\title{
Analisa Tingkat Pengetahuan Keislaman Dosen Fakultas Sains dan Teknologi UIN Suska Riau dalam Upaya Mewujudkan Integrasi Keislaman Menggunakan Metode Analytical Hierarchy Process (Ahp)
}

\author{
Ismu Kusumanto ${ }^{1}$, Ekie Gilang Permata $^{2}$ Nofirza $^{3}$, Wresni Anggraini ${ }^{4}$ \\ 1,2,3,4 Jurusan Teknik Industri, Fakultas Sains dan Teknologi UIN Sultan Syarif Kasim Riau \\ J1. HR. Soebrantas no. 155 Panam, Pekanbaru \\ Email: ismu_uin@yahoo.co.id
}

\begin{abstract}
ABSTRAK
Visi UIN Suska Riau yang menintegrasikan ajaran Islam, Ilmu Pengetahuan, Teknologi dan/atau Seni menuntut kesiapan civitas akademika untuk mewujudkannya. Kesiapan tersebut dapat dilihat salah satunya dari tingkat pengetahuan ajaran Islam beserta ilmu-ilmu pendukungnya sebelum melakukan integrase dengan ilmu pengetahuan umum dan teknologi dan/atau seni. Penelitian deskriptif kuantitatif menggunakan metode AHP untuk melihat tingkat pengetahuan ajaran Islam para dosen yang ada di Fakultas Sains dan Teknologi UIN Suska Riau. Hasil penelitian menunjukkan bahwa Factor yang cukup baik adalah pengenalan kosa kata umum bahasa Arab dan Pengetahuan dasar al-Qur'an. Sedangkan faktor yang kurang baik adalah pelaksanaan ibadah dan wawasan umum keislaman. Sementara factor yang sangat tidak baik adalah tokoh Islam dan sejarah Islam dan pengetahuan hadits. Berdasarkan hasil penelitian maka perlu dilakukan pelatihan untuk meningkatkan pengetahuan dan wawasan keislaman dosen Fakultas Sains dan Teknologi berdasarkan prioritas adalah sebagai berikut Pembelajaran bahasa Arab (sebagai dasar memahami teks ajaran agama Islam), Pembelajaran al-Qur'an sebagai pedoman utama umat Islam, Pembelajaran hadist sebagai penjelasan ayat-ayat al-Qur'an dan pedoman umat Islam, Peningkatan pelaksanaan ibadah dan muamallah, Pembelajaran terkait tokoh dan sejarah Islam yang telah menginspirasi dunia sehingga timbul motivasi, dan Peningkatan wawasan keislaman
\end{abstract}

Kata Kunci : Visi, Pengetahuan Keislaman, AHP

\section{Pendahuluan}

Visi UIN Sultan Syarif Kasim (Suska) Riau adalah terwujudnya Universitas Islam Negeri sebagai lembaga pendidikan tinggi pilihan utama pada tingkat dunia yang mengembangkan ajaran Islam, ilmu pengetahuan, teknologi dan/atau seni secara integral pada tahun 2023. Visi merupakan harapan dan arahan seluruh sivitas akademika UIN Suska Riau yang harus diwujudkan secara bersama. Menjadi terkemuka pada tingkat dunia dalam integrasi keislaman, pengetahuan dan teknologi serta seni merupakan suatu harapan yang tinggi, hal tersebut menuntut kesiapan seluruh sivitas akademika UIN Suska Riau dalam upaya mewujudkan visi tersebut, terutama dosen sebagai unsur utama dalam proses pengajaran dan pendidikan.

Upaya mewujudkan integrasi keislaman dan keilmuan sampai saat ini belum memenuhi harapan sebagaimana yang diinginkan, bahkan terkesan "jalan ditempat". Penelitian yang dilakukan oleh Nurmaini Dalimunthe (2015) terhadap implementasi integrasi keislaman dan keilmuan di UIN Suska Riau dan UIN Malik
Ibrahim Malang menunjukkan bahwa implementasi integrasi keislaman dan keilmuan belum memiliki konsep operasional yang jelas dan dapat diterapkan. Thoyyar (2009) telah menulis sebuah makalah yang dipublikasikan pada Annual Conference on Islamic Studies IX yang berjudul Model-model integrasi ilmu dan upaya membangun landasan keilmu-an, menerangkan bahwa masih terlalu banyak model integrasi keilmuan yang berbeda-beda sehingga menyulitkan dalam memahami dan melaksanakannya.

Kondisi ini disebabkan tidak ada kemajuan dalam mewujudkan integrasi keislaman dan keilmuan secara signifikan, baik karena model integrasi yang belum dapat dioperasionalkan maupun kesiapan dosen untuk mewujudkan integrasi keislaman dan keilmuan relatif kurang. Segala upaya tentu akan terkendala karena dosen sebagai unsur utama terwujudkan integrasi keislaman dan keilmuan.

Para dosen FST umumnya dari pendidikan umum yang tidak mendapat ilmu Islam secara mendalam. Pengeta-huan Islam sering 
diperoleh dari MDA saat sekolah dasar dan tidak berkembang saat remaja dan dewasa. Sebagian besar dosen hanya mendapatkan pelajaran Agama Islam di sekolah masing-masing sekali seminggu, tanpa ada tambahan pengetahuan lain. Hal ini tentu tidak memadai dalam upaya mewujudkan integrasi keislaman dan keilmuan, dimana untuk dapat mewujud-kan integrasi tersebut minimal menguasai dasar-dasar pengetahuan keislaman utama, seperti al-Qur'an, hadits, fiqih, muamalah, akhlak, ibadah dan unsur pendukung pengetahuan keislaman lainnya, seperti Bahasa Arab.

\section{Tinjauan Pustaka}

\section{Pengertian Integrasi Ilmu}

Secara bahasa, John M. Echols dan Hassan Shadily dari kamus Bahasa Inggris-Indonesia (dikutip dari Dalimunthe, 2015) mengartikan bahwa integration merupakan kata serapan dengan istilah "integrasi" yang dapat diartikan sebagai "menyatu-padukan atau menggabungkan". Sedangkan pengertian integrasi secara terminologi adalah pemanduan antara ilmu-ilmu yang terpisah menjadi satu kepaduan ilmu. Dalam pengertian ini, maka yang dimaksud integrasi adalah penyatuan antara ilmu-ilmu yang bercorak agama dengan ilmu-imu yang bersifat umum, khususnya ilmu eksakta. Hal ini dimaksudkan untuk meniadakan polarisasi atau dikotomi antara ilmu agama dan ilmu umum (eksakta).

Konsep utama integrasi keilmuan adalah semua ilmu berasal dari Allah (all tre knowledge is from Allah). Konsep ini disampaikan pula oleh M. Amir Ali (dikutip oleh Dalimunthe, 2015) yaitu all correct theories are from Allah and false theories are from men themselves or inspired by satan (semua ilmu datang dari Allah dan ilmu yang menyesatkan/keliru berasal dari manusia atau terinspirasi dari setan). Sementara Huzni Thoyyar (2009) menyatakan sebagai "knowledge is the light that comes from Allah".

Pada abad $7 \mathrm{M}$ hingga abad $15 \mathrm{M}$, dunia Islam tidak membedakan antara ilmu umum dan ilmu agama secara nyata. Banyak ulama besar yang menguasai ilmu agama maupun ilmu umum (eksakta), seperti Ibnu Sina dan Aljabar. Dikotomi (pemisahan) antara ilmu agama dan ilmu dimulai saat dunia Islam mengalami masa-masa stagnan $(1250-1800 \mathrm{M})$, dimana pengaruh fuqaha sangat kuat yang menggolongkan ilmu agama sebagai fardhu 'ain dan ilmu umum sebagai fardhu kifayah yang tidak wajib dikuasai oleh seluruh umat Islam. Kondisi tersebut ditambah dengan serbuan pasukan Tartar ke kota Bagdad sebagai pusat Kekhalifahan Abbasiyah yang menghan-curkan banyak perpustakaan dan membunuh para ulama teknokrat. Serangan tentara salib juga turut memun-durkan dunia Islam sehingga banyak daerah muslim yang direbut tentara salib. Untuk mempertahankan
Jurnal Hasil Penelitian dan Karya Ilmiah dalam Bidang Teknik Undustri jatidiri (Islam) maka banyak penguasa Islam zaman itu yang melarang ijtihad dan memberlakukan ketaatan mutlak pada syari'ah sehingga menimbulkan kejumudan. (Ambat, 2014)

\section{Pembagian Pengetahuan Keislaman}

Pengetahuan keislaman dapat dibagi dua, yaitu Kelompok ilmu-ilmu Fardu 'ain dan Kelompok ilmu-ilmu Fardu kifayah..

\section{Ilmu Fardu 'ain}

Pengertian ilmu fardu 'ain, merujuk pada Syaikh Muhammad Sholeh Al-'Utsaimin rahimahullah, (dalam http://www.alifta.net) yaitu: 1. Jenis ilmu Fardu 'ain yang disebutkan oleh Imam Ahmad An-Nawawi dan Ulama Lajnah Daimah KSA rahimahumullah, seperti : mengetahui tauhid dan kebalikan-nya, yaitu syirik, pokok-pokok keimanan (Rukun Iman) dan Rukun Islam, hukum-hukum sholat, tatacara wudhu', bersuci dari junub, termasuk mengetahui perkaraperkara yang diharomkan dalam Islam.

2. Jenis ilmu Fardu 'ain yang harus dipelajari oleh sebagian mukallafiin, yang memiliki kewajiban tertentu yang khusus baginya. Seperti konsep fardu kifayah, namun lebih bersifat khusus. Contohcontoha diantaranya adalah :

- Ilmu tentang ibadah tertentu bagi orang yang mampu mengerjakannya.

- Ilmu tentang profesi atau tugas, agar menunaikan kewajiban pekerjaana dan terhindar melakukan keharoman dalam pekerjaannya.

- Ilmu tentang mu'malah (aktivitas) yang hendak dilakukannya, agar menghindari larangan yang haram dilakukan dan bisa menunaikan kewajibannya terhadap pihak lain.

- Ilmu tentang hukum suatu kejadian kontemporer.

\section{Ilmu Fardhu Kifayah}

Pengertian fardhu kifayah adalah sebuah ilmu yang jika sudah ada sebagian kaum muslimin mempelajarinya, maka gugur kewajiban atas seluruh kaum muslimin, namun tetap disunnahkan kaum muslimin yang lain untuk mempelajarinya. Ilmu Fardhu Kifayah pun terbagi menjadi dua, yaitu yang terkait dengan ilmu-ilmu Syar'i dan yang terkait dengan ilmu-ilmu dunia.

\section{Metode Penelitian}

\section{Hipotesa dan Variabel Operasional}

\section{a. Hipotesa}

Hipotesa penelitian adalah, tingkat pengetahuan keislaman dosen FST berpengaruh terhadap terwujudnya visi UIN Suska Riau dalam integrasi keilmuan dan Islam. Dugaan awal, tingkat pengetahuan keislaman dosen FST relatif kurang memadai sehingga menjadi kendala utama terwujudnya integrasi keilmuan dan Islam. 
Vol. 5, No. 1, 2019

b. Variabel Operasional

Variabel operasional adalah,

1. Tingkat pengetahuan Al-Qur'an dan tafsirnya

2. Tingkat pengetahuan Hadits dan pemahamannya

3. Tingkat pengetahuan tentang fiqih dan ushul fiqih

4. Tingkat pengetahuan tentang akhlak dan muamallah

5. Tingkat pengetahuan bahasa arab

6. Kebiasaan ibadah

7. Latar belakang pendidikan agama
Jurnal Hasil Penelitian dan Karya Ilmiah dalam Bidang Teknik Undustri

Populasi penelitian adalah seluruh dosen tetap FST UIN Suska Riau, baik PNS maupun Non PNS dengan sample sesuai rumus Slovin adalah 50 orang. Penelitian tidak melibatkan seluruh popu-lasi karena adanya beberapa faktor, yaitu

1. Terdapat dosen FST UIN Suska Riau yang sedang dalam tugas belajar, sebanyak 15 orang.

2. Adanya penolakan dari beberapa orang dosen untuk memberikan informasi terkait tingkat pengetahuan keislaman sehingga jumlah data tidak memenuhi populasi.

\section{Populasi dan Sample}

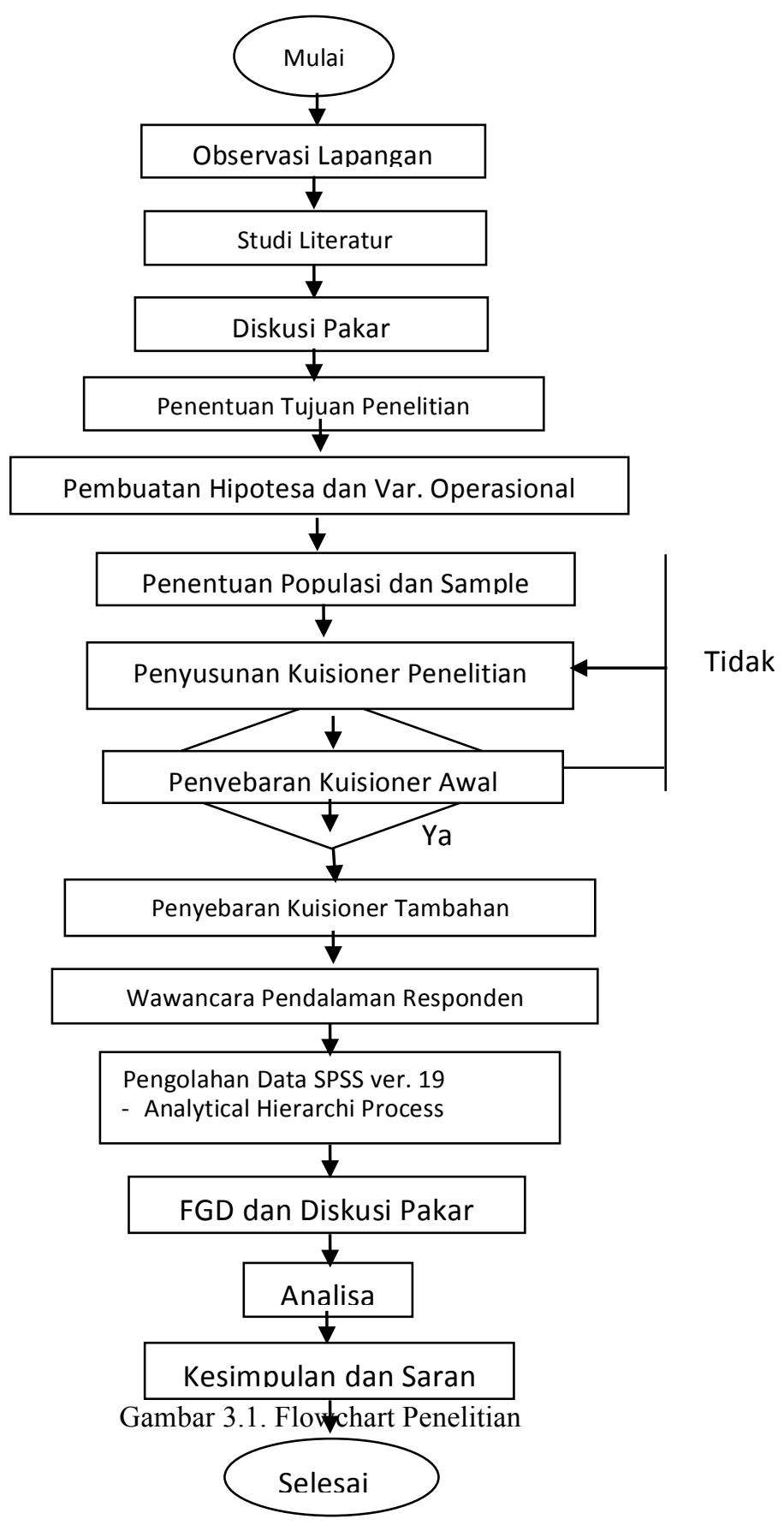




\section{Hasil dan Pembahasan}

\section{Data Dosen Fakultas Sains dan Teknologi UIN Suska Riau}

Dosen di Fakultas Sains dan Teknologi UIN Suska Riau 66,4 \% berstatus PNS dan telah menerima sertifikasi pendidik sehingga diakui sebagai pendidikan professional. Sementara masih ada $33,6 \%$ dosen berstatus non-PNS yang sebagian belum tersertifikasi pendidik. Beberapa dosen berstatus pegawai dan tidak dapat dimasukkan dalam katagori dosen tetap FST UIN Suska, karena tidak dapat menyelesaikan pendidikan S2 pada 1 Januari 2017 sebagai syarat menjadi dosen professional. Jumlah dosen yang berstatus pegawai tersebut 22 orang,. Sepertiga dosen masih berstatus dosen tetap non-PNS dengan sebagian belum mendapatkan sertifikasi pendidik professional..

Dosen bergelar S3 sebesar 7,4 \% dan S2 sejumlah 92,6\%. Kondisi ini baru memenuhi standar minimal pelaksanaan pendidikan tinggi. Kualitas dosen akan lebih menyakinkan bila memiliki kemampuan wawasan integrasi Islam dan ilmu pengetahuan dengan baik.

\section{Hasil Pengolahan Data}

\section{a. Pengetahuan al-Qur'an}

Jawaban responden atas pertanyaan terkait Pengetahuan al-Qur'an, $61 \%$ mengaku memiliki pengetahuan yang baik. Bila melihat jawaban responden, nilai tertinggi ada pada partanyaan 1, "Saya mampu membaca al-Qur'an dengan baik" namun saat dilakukan wawancara langsung pada kelompok tahsin maka sangat sedikit dosen memiliki kemampuan maghorijul huruf dan tajwid yang baik. Dikaitkan dengan kemampuan tafsir dan hafalan tentu akan sangat rendah.

Indikasi tersebut terlihat pada pertanyaan 4, "Saya hafal juz amma", maka hanya sekitar $3 \%$ dosen yang hafal seluruh juz amma. Bahkan ada 58 $\%$ yang kurang baik hafalan juz amma, atau hanya mampu menghafal surat-surat pendek didalam juz amma. Sementara dosen yang pernah membaca buku tafsir, terdapat kurang dari $45 \%$, dengan kualitas pema-haman yang relative kurang disebabkan kemampuan bahasa Arab dan ilmu pendukung lain yang juga minim.

Pertanyaan 21, "Saya mengetahui ayat alQur'an tentang gunung-gunung bergerak cepat," lebih dari $62 \%$ mengaku memahami makna ayat tersebut dan hanya $15 \%$ yang tidak memahami sama sekali.

\section{b. Pengetahuan Hadits}

Umumnya responden mengakui bahwa pengetahuan hadits lemah, dimana $30 \%$ mengaku memiliki pengetahuan hadist yang baik dan $70 \%$ mengakui tidak menguasai pengetahuan terkait hadits.

$$
\text { Banyak responden mengaku telah }
$$
membaca kitab-kitab hadist, seperti Sahih Muslim,
Jurnal Hasil Penelitian dan Karya Ilmiah dalam Bidang Teknik Undustri walaupun tidak menguasai dan belajar secara sistematis. Namun bila pertanyaan terkait ashbabul furud dan kitab syara' hadits maka hanya $25 \%$ yang mengaku telah belajar dan membacanya.

\section{c. Bahasa Arab}

Pertanyaan pengenalan bahasa Arab, pertama adalah pengenalan kata dan tulisan bahasa Arab, sekitar $70 \%$ mengaku mengenal dengan baik kesalahan yang ditampilkan didalam kuisioner. Namun saat pertanyaan pada kemampuan nahwu shorof maka kebalikannya, $70 \%$ yang mengaku tidak memiliki kemampuan nahwu shorof dengan baik. Hal ini menunjukkan bahwa kemampuan mem-baca tulisan Arab telah cukup baik, tetapi untuk pengetahuan bahasa Arab maka kemampuan responden relatif rendah.

\section{d. Tokoh dan Sejarah}

Pengenalan tokoh muslim dan sejarah Islam merupakan faktor relatif rendah dibandinng faktor lain. Hal ini dapat dilihat bahwa pertanyaan tentang perang Shiffin di zaman Khalifah Ali bin Abi Thalib dan sejarah perang Toledo di Eropa tidak ada yang menjawab D. Sekitar $75 \%$ mengaku tidak tahu sejarah tersebut.

\section{e. Pelaksanaan Ibadah}

Faktor pelaksanaan ibadah relatif baik, walaupun perlu ditingkatkan. Nilai pelaksanaan ibadah yang telah dijalankan dengan baik sekitar 59 $\%$. Namun kondisi ini tidak sepenuhnya dilaksanakan sebagai sebuah amal ibadah yang ikhlas.

Variabel puasa sunnah adalah variabel dengan nilai yang paling rendah, sekitar $70 \%$ tidak melaksanakan puasa senin kamis.

\section{f. Wawasan Keislaman}

Secara umum, responden mengaku $53 \%$ memahami dasar-dasar penetapan suatu hukum ibadah maupun muamallah dan hanya $47 \%$ yang tidak memahami dengan baik. Hal ini menjadi perhatian karena penguasaan dasar-dasar penetapan suatu hukum sangat penting bagi para dosen di FST UIN Suska Riau.

Bila diperhatikan setiap variable pertanyaan, maka kelemahan dalam factor wawasan keislaman ada pada variable 8 (ayat dan hadist sesuai bidang ilmu), variable 12 (pemahaman ushul fiqh), dan variable 19 (perbandingan mazhab). Namun dari ketiga variable yang kurang dipahami tersebut, pemahaman ushul fiqh adalah paling tidak dipahami.

Sementara, wawasan keislaman yang paling dipahami oleh responden adalah variabel 9 (dasar hukum muamala) dan variable 20 (dalil terhadap ibadah). Kondisi ini dapat tercipta dikarenakan responden telah cukup sering mendengar pengajian maupun kajian agama di berbagai tempat.

\section{Analytical Hierarchy Process}


Tabel 21. Hasil pengolahan AHP

\begin{tabular}{|c|c|}
\hline Atribut AHP & Bobot nilai \\
\hline Al-Qur'an & 0.390 \\
\hline Hadits & 0.129 \\
\hline Bhs Arab & 0.195 \\
\hline Tokoh-Sejarah & 0.044 \\
\hline Ibadah & 0.078 \\
\hline Wawasan Islam & 0.013 \\
\hline JUMLAH & 1,00 \\
\hline
\end{tabular}

Hasil pengolahan AHP memberikan hasil berdasarkan skala prioritas adalah,

a. Pengetahuan al-Qur'an

Pemahaman al-Qur'an menjadi dasar setiap muslim dalam menjalankan keyakinan beragama Islam. Walaupun sebagai muslim belum memiliki pengetahuan pendukung agama yang lain, serendah apa pun seorang muslim harus mulai dari belajar al-Qur'an, baru kemudian mempelajari ilmu lainnya.

Namun tentu belajar memahami al-Qur'an harus didampingi seorang ulama yang paham al-Qur'an dengan baik dan tidak semata-mata belajar memahami al-Qur'an secara otodidak. Hal ini penting karena orang awam akan mudah salah dalam memahami al-Qur'an apabila tidak didampingi oleh ulama yang baik.

Dengan demikian, menempatkan belajar pengetahuan seputar al-Qur'an sebagai prioritas pertama adalah suatu hal yang dapat diterima kebenarannya.

b. Penguasaan Bahasa Arab

Bahasa Arab adalah bahasa utama dalam Islam, karena al-Qur'an dan Hadits serta teksteks utama keislam-an ditulis para ulama besar dalam Bahasa Arab, sehingga bagi umat muslim yang ingin memperdalam agama Islam maka wajib mempelajari bahasa Arab.
Jurnal Hasil Penelitian dan Karya Ilmiah dalam Bidang Teknik Undustri Melihat skor yang dihasilkan dalam pengolahan AHP yang berbeda tipis antara penguasaan Bahasa Arab dan Pengetahuan Hadits maka pada hakekatnya kedua ilmu tersebut dapat disamakan dalam prioritas belajarnya. Namun bahasa Arab lebih dahulukan sedikit dengan pertimbangan akan semakin memahami kandungan al-Qur'an dan Hadits yang dipelajari tersebut.

c. Pengetahuan Hadits

Belajar Hadits dan Bahasa Arab relative sama skala prioritasnya, sehingga tidak ada perbedaan men-colok untuk ilmu yang didahulukan belajarnya. Belajar ilmu hadits penting karena banyak ayat-ayat al-Qur'an yang perlu dijelaskan lebih rinci sehingga bisa dilaksanakan.

d. Pelaksanaan Ibadah

Pemahaman dan tingkat keimanan seseorang tercermin dari pelaksanaan ibadahnya. Oleh sebab itu, ibadah menjadi prioritas bagi dosen untuk diterapkan. .

e. Tokoh dan Sejarah Islam

Mempelajari tokoh dan sejarah Islam dengan baik akan motivasi untuk lebih mendalami Islam dengan baik..

f. Wawasan Keislaman

Belajar wawasan Keislaman menjadi penting karena dalam menghadapi persoalan dunia yang komplek, seorang muslim harus memiliki bekal pengetahuan yang memadai. Perang pemikiran dan saling mempengaruhi antar kelompok menjadi sangat kritis bagi seorang muslim.

\section{Kurikulum Pelatihan Pengembagan Pengetahuan Agama Dosen}

Kurikulum pelatihan pengembang-an pengetahuan agama Islam bagi dosen FST UIN Suska Riau disusun secara sistematis agar memudahkan dalam pencapaian target pengetahuan yang harus dimiliki setiap dosen. Penyusunan kurikulum dilakukan dengan melihat hasil pengolahan data menggunakan AHP. Matrik kurikulum pelatihan adalah sebagai berikut.

Tabel 22. Matrik kurikulum pelatihan pengembangan pengetahuan agama

\begin{tabular}{|l|l|}
\hline \multicolumn{1}{|c|}{ Bidang Keilmuan } & \multicolumn{1}{c|}{ Topik Pelatihan } \\
\hline \multirow{3}{*}{ Pengetahuan al-Qur'an } & - Sejarah al-Qur'an \\
& - Klasifikasi ayat-ayat al-Qur'an \\
& - Tshababul Nuzul \\
& - Usaha-usaha melemahkan al-Qur'an \\
\hline \multirow{3}{*}{ Bahasa Arab } & - Pendahuluan \\
& - Pengenalan tata bahasa Arab \\
\hline Pengetahuan Hadits & - Nahwu - sharaf \\
\hline
\end{tabular}




\begin{tabular}{|c|c|}
\hline & $\begin{array}{l}\text { - Klasifikasi Hadits } \\
\text { - Sanad-Matan Hadits } \\
\text { - Ashababul Furud } \\
\text { - Tafsir Hadits } \\
\text { - Usaha-usaha melemahkan Hadits }\end{array}$ \\
\hline Pelaksanaan Ibadah & $\begin{array}{ll}\text { - Sejarah Hadits } \\
\text { - Klasifikasi Hadits } \\
\end{array}$ \\
\hline $\begin{array}{l}\text { Tokoh dan Sejarah } \\
\text { Islam }\end{array}$ & $\begin{array}{l}\text { - Ayat dan Hadits terkait kewajiban menjadi orang berilmu dan meninggalkan ilmu } \\
\text { - Tokoh-tokoh besar Islam pada zamannya } \\
\text { - Tokoh Islam zaman modern } \\
\text { - Karakteristik tokoh Islam } \\
\end{array}$ \\
\hline Wawasan Keislaman & $\begin{array}{l}\text { - Ushul fiqih } \\
\text { - Aqidah akhlak } \\
\text { - } \text { Fiqih } \\
\text { - } \text { Muamalah } \\
\text { - } \\
\text { Ibadah } \\
\end{array}$ \\
\hline
\end{tabular}

\section{Kesimpulan}

Kesimpulan yang diperoleh adalah sebagai berikut,

a. Factor yang cukup baik adalah

- Bahasa Arab (pengenalan kosa kata umum bahasa Arab) : $62 \%$

- Pengetahuan al-Qur'an : $61 \%$

Khusus bahasa Arab, pengenalan kosa kata umum bahasa Arab sudah baik, termasuk mengenali tulisan Arab. Namun, untuk tata bahasa Arab masih sangat minim.

b. Faktor yang kurang baik adalah,

- Pelaksanaan ibadah : $59 \%$

- Wawasan keislaman : $53 \%$

c. Factor yang sangat tidak baik adalah,

- Tokoh dan sejarah Islam : $25 \%$

- Pengetahuan hadits : $30 \%$

Berdasarkan hasil penelitian, maka pelatihan untuk meningkatkan pengetahu-an dan wawasan keislaman dosen FST berdasarkan prioritas adalah,

1. Pembelajaran bahasa Arab (dasar memahami teks ajaran Islam).

2. Pembelajaran al-Qur'an, sebagai pedoman utama umat Islam.

3. Pembelajaran hadist, sebagai penjelasan ayat-ayat al-Qur'an dan pedoman umat Islam

4. Peningkatan pelaksanaan ibadah dan muamallah

5. Pembelajaran tokoh dan sejarah Islam yang telah menginspirasi dunia

6. Peningkatan wawasan keislaman

\section{Daftar Pustaka}

[1] Ambat, Harto Embung. 2014. Dikotomi ilmu dalam peradaban Islam. Pustaka Dunia, Jakarta
[2] Dalimunthe, Nurmaini dan Khairunsyah Purba. 2015. Impelemntasi integrasi ilmu di Universitas Islam Negeri (Studi komparatif antara UIN Suska Riau dengan UIN Maulana Malik Ibrahim Malang). LPPM UIN Suska Riau, Pekanbaru

[3] Hasan, M. Iqbal. 2002. Pokok-pokok Materi Metodologi Penelitian dan Aplikasinya. Ghalia Indonesia. Jakarta.

[4] Noor, Juliansyah. 2011. Metdologi Penelitian Skripsi, Tesis, Disertasi, dan Karya Ilmiah. Kencana. Jakarta.

[5] Thoyyar, Huzni. 2009. Model-model integrasi ilmu dan upaya membangun landasan keilmuan : Survey literatur terhadap pemikiran Islam kontemporer. Makalah Annual Conference Islamic studies IX. 4 Nopember 2009

[6] Ukkasyah, Sa'id Abu. 2015. Skala Prioritas dalam Belajar Agama Islam. Available : http://www.alifta.net 